\title{
INTERVERTEBRAL VEINS DIRECTLY CONNECTING THE VERTEBRAL VENOUS SYSTEM TO THE AZYGOS VENOUS SYSTEM RATHER THAN THE PROXIMAL END OF THE POSTERIOR INTERCOSTAL VEINS
}

\author{
Naief Dahran $^{1,2}$, Roger Soames ${ }^{1}$ \\ ${ }^{1}$ Centre for Anatomy and Human Identification, College of Art, Science and Engineering, \\ University of Dundee, Dundee, United Kingdom \\ ${ }^{2}$ Department of Anatomy, College of Medicine, University of Jeddah, Jeddah, Kingdom of \\ Saudi Arabia
}

\begin{abstract}
RESUMEN
La estructura de las venas de la cavidad torácica varía significativamente en función de sus conexiones. Treinta cadáveres embalsamados con la técnica de Thiel fueron disecados (18 mujeres, 12 hombres), con edades comprendidas entre 48 y 98 años (media $81.3 \pm 12.40)$. Los pulmones, el corazón, la aorta torácica, el esófago y la pleura parietal fueron cuidadosamente retirados para permitir la visualización de las venas ácigos, hemiácigos y hemiácigos accesoria así como el conducto torácico. En la mayoría de los especímenes (21) se encontró que las venas intervertebrales estaban directamente conectadas con el sistema venoso ácigos en vez de con la parte terminal proximal de las venas intercostales posteriores. Se observó también que dicha distribución es más común en el lado derecho, pero no en todos los niveles vertebrales. Estas conexiones podrían jugar un rol en la regulación del volúmen de sangre entre los sistemas venosos ácigos y vertebral: también podrían actuar como vías metastásicas entre las regiones torácica y abdominal. Dado que su aspecto es bastante similar al de los vasos intercostales posteriores, es importante que los cirujanos sean conscientes de esta variación para evitar lesiones que induzcan hematomas postoperatorios.
\end{abstract}

Palabras clave: Ácigos, intervertebral, Intercostal posterior, embalsamamiento Thiel, torácico.

\begin{abstract}
Veins in the thoracic cavity are highly variable in terms of their communications. Thirty Thiel-embalmed cadavers were dissected (18 females and 12 males), ranging in age from 48 to 98 years old (mean 81.3 \pm 12.40 ). The lungs, heart, thoracic aorta, oesophagus and parietal pleura were removed carefully to expose the azygos, hemiazygos, accessory hemiazygos veins and thoracic duct. In most specimens (21) intervertebral veins were connected directly to the azygos venous systems rather than the proximal end of the posterior intercostal veins. This presentation was observed to be more common on the right side, but not at all vertebral levels. These communications could play a role in regulating blood volume between the azygos and vertebral venous systems; they may also act as metastatic pathways between the thoracic and abdominal regions. As they mimic posterior intercostal vessels, it is important for surgeons to be aware of this variation to avoid injuries leading to postoperative hematomas.
\end{abstract}

Keywords: Azygos, intervertebral, posterior intercostal, Thiel-embalmed, thoracic.

\footnotetext{
* Correspondence to: Dr Naief Dahran. Centre for Anatomy and Human Identification (CAHID), College of Art, Science and Engineering, University of Dundee, Dundee, DD1 5EH, UK.n.dahran@gmail.com
}

Received: 16 April, 2015. Revised: 13 May, 2015. Accepted: 1 June, 2015. 


\section{INTRODUCTION}

Three main veins form the azygos venous system: the azygos (AV), hemiazygos (HV) and accessory hemiazygos (AHV) veins (Drake et al, 2005; Snell, 2004). The AV is embryologically derived from the right azygos line, starting caudally from the union of the right subcostal vein and right ascending lumbar vein. It ascends cranially to drain the lower eight right posterior intercostal veins (RPIVs) into the superior vena cava at the level of T3 (Standring et al, 2008), receiving along its course the $\mathrm{HV}, \mathrm{AHV}$, mediastinal, pericardial, oesophageal, right bronchial and right superior intercostal veins (Drake et al, 2005; Snell, 2004). The hemiazygos system (HV and AHV), together with the left superior intercostal vein, drains the lower eight left posterior intercostal and upper four left posterior intercostal veins (LPIVs) into the azygos vein and left brachiocephalic vein, respectively.

The posterior intercostal veins (PIVs) drain the lateral and posterior aspects of the intercostal spaces and open directly or indirectly into the AV. The intervertebral veins (IVVs) connect the vertebral venous system with the azygos venous system indirectly via the PIVs. A complete valve is located at the proximal end of each PIV (Maros, 1981), which allows venous blood to drain into the vertebral venous system via the IVV (Hoogland et al, 2013).

The main aims of this study were to examine the anatomical variations of the azygos venous system and compare the observations with existing classification systems, applying modifications as appropriate. This study showed that, commonly, IVVs are connected to the azygos venous system instead of the proximal part of the PIVs. This observation is important because these veins could have a role in regulating blood volume between the azygos and vertebral venous system. Moreover, they may act as metastatic pathways between the thoracic and abdominal regions.

\section{MATERIALS AND METHODS}

Thirty Thiel-embalmed cadavers (18 females and 12 males) were examined. They had been used for dissection by science and medical students in the Centre for Anatomy and Human Identification (CAHID), University of Dundee, Scotland. The cadavers ranged in age from 48 to 98 years old (mean 81.3 \pm 12.40 ).

The lungs, heart, thoracic aorta and oesophagus were removed and the AV, HV, AHV and thoracic duct exposed by carefully removing the parietal pleura. The diaphragm was depressed to reveal the origin of the AV and HV.

Subsequently, the azygos system was cleaned. Three coloured pins were inserted into the anterior surface of the thoracic vertebrae: a green pin indicating level T12, a white pin indicating level T8 and a red pin indicating level T5 (Fig. 1). Photographs were taken and a schematic drawing of each specimen was made.

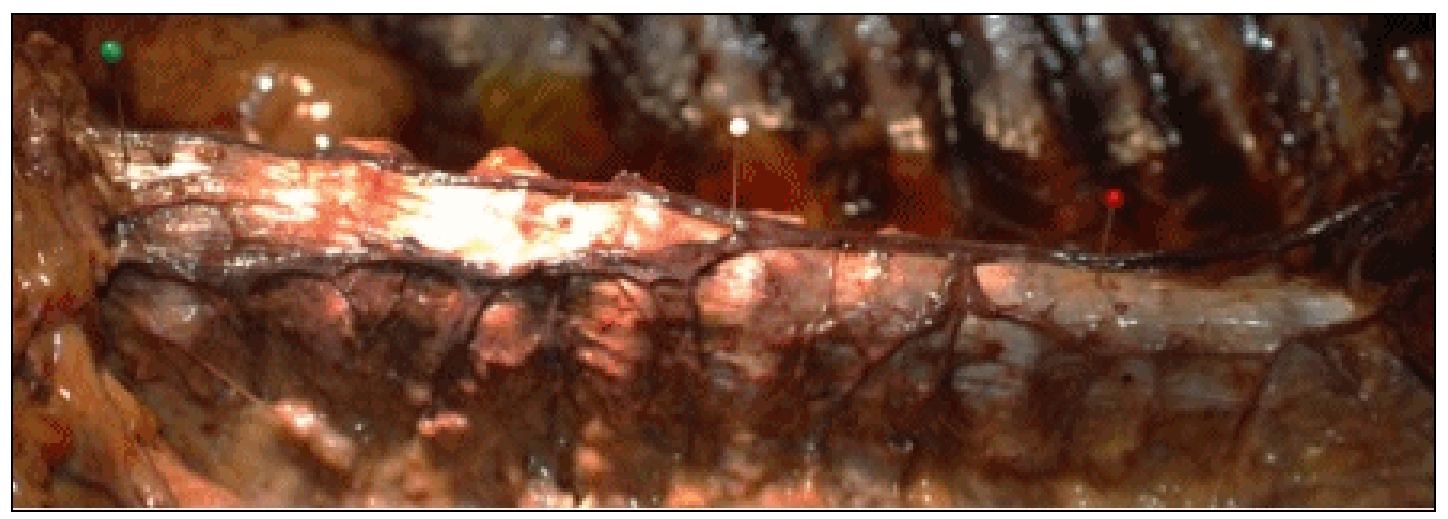

Figure 1: Pins indicating the vertebral levels T12 (green pin), T8 (white pin) and T5 (red pin).

\section{RESULTS}

Of the 30 cadavers examined, $21(70 \%)$ had intervertebral veins (IVV) connecting directly to the azygos venous system on both sides, but not at all vertebral levels. Moreover, some had communications with adjacent posterior intercostal veins from their proximal aspects. These veins were commonly less than $1 \mathrm{~mm}$ in diameter and adjacent to the posterior intercostal veins. 
Although they were observed on both sides, they were more common on the right (Fig. 2 and 3).

On the right side, T7 and T8 were the most common levels at which intervertebral veins connected directly to the azygos venous system.
Table 1 shows the frequency of these veins at each vertebral level. There was no significant correlation between gender and the presentation of these communications.

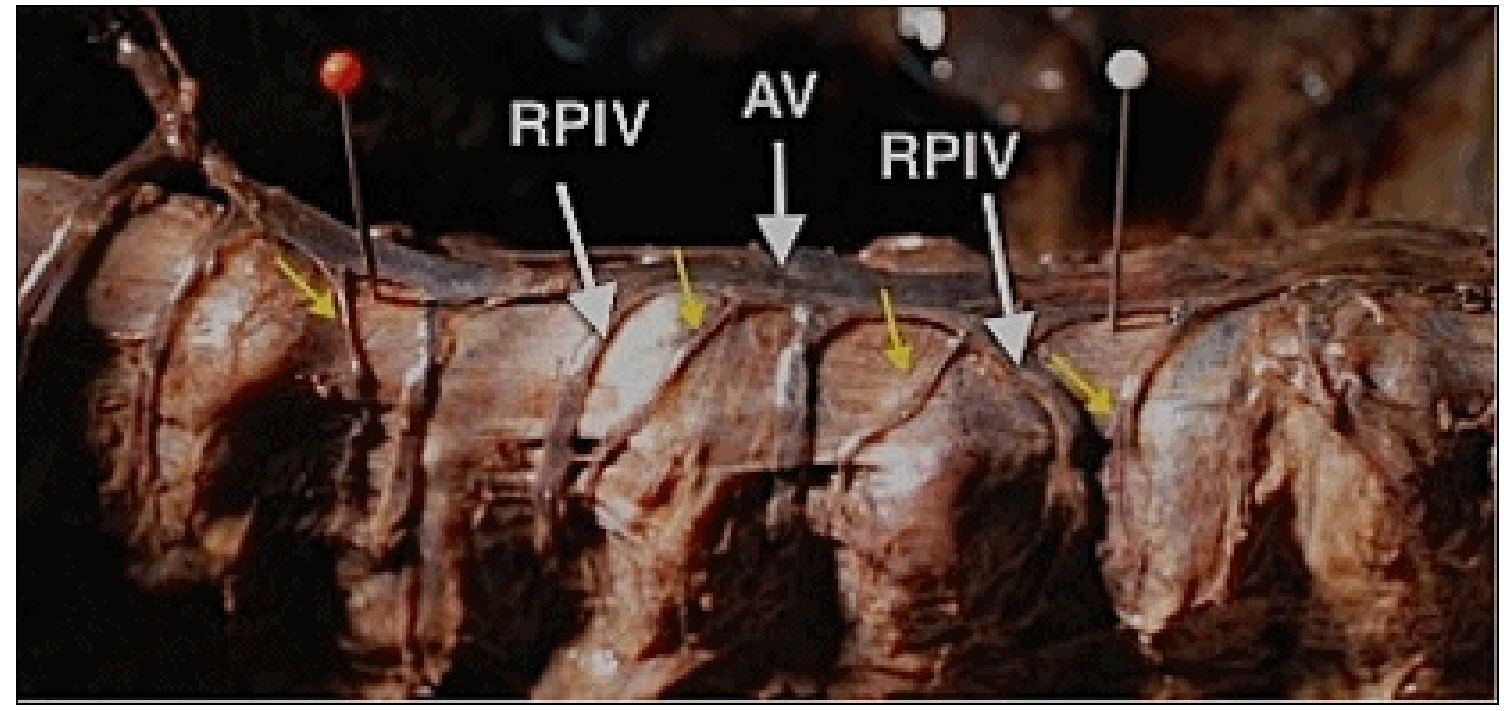

Figure 2: Intervertebral veins adjacent to the right posterior intercostal veins (RPIV) found in most specimens (yellow arrows) connecting directly to the azygos vein (AV).

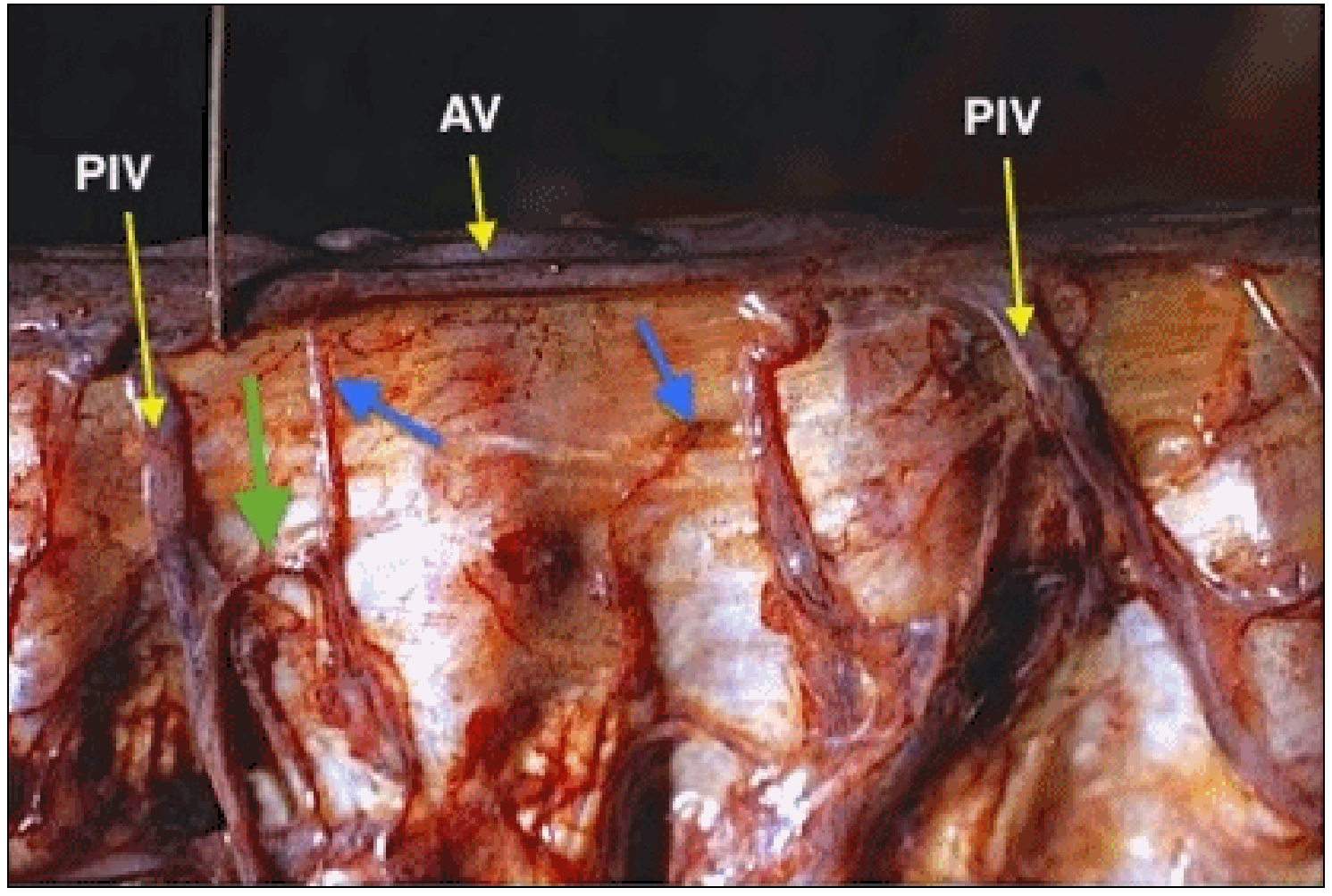

Figure 3: Right side view showing the intervertebral veins (blue arrows) adjacent to the posterior intercostal veins (PIV) and connecting to the azygos vein. The green arrow indicates the communication between an intervertebral vein and PIV. 


\begin{tabular}{|c|c|c|}
\hline \multirow{2}{*}{ Vertebral } & \multicolumn{2}{|c|}{ Frequency } \\
\cline { 2 - 3 } & Right Side & Left Side \\
\hline T1 & 0 & 0 \\
\hline T2 & 0 & 0 \\
\hline T3 & 1 & 0 \\
\hline T4 & 1 & 0 \\
\hline T5 & 3 & 0 \\
\hline T6 & 4 & 0 \\
\hline T7 & 11 & 2 \\
\hline T8 & 11 & 2 \\
\hline T9 & 7 & 2 \\
\hline T10 & 6 & 0 \\
\hline T11 & 4 & 0 \\
\hline T12 & 0 & \\
\hline
\end{tabular}

Table 1: The frequency of intervertebral veins draining directly into the azygos vein at each vertebral level found in $70 \%$ of the specimens $(N=21)$.

\section{DISCUSSION}

In the majority of specimens examined $(N=21)$, the IVVs were observed to connect the azygos and vertebral venous systems directly on both the right and left sides. These veins were frequently less than $1 \mathrm{~mm}$ in diameter and located close to the proximal part of the corresponding posterior intercostal vein: they were found on both sides, but were more common on the right side. The small veins reported here were incidental observations of the main study.

In general IVVs, which connect directly to the azygos venous system, are small vessels not often seen during dissection of the thorax. The present observations were most probably due to the specimens being Thiel and not formalinembalmed. In formalin embalming they are damaged easily during removal of the parietal pleura. It is also unlikely that these small vessels would be visualized in radiological procedures. The present observations do not appear to have been reported previously in the literature.

According to Hoogland et al (2013), the vertebral venous system connects with the proximal part of the posterior intercostal veins via IVVs: they are considered to play an important role in heat transportation from the posterior intercostal veins to the vertebral venous system. Hoogland et al concluded that PIVs are essential anastomoses between the internal vertebral venous plexus and the AV. With respect to Hoogland et al it is possible that IVVs connect to the azygos vein instead of the proximal part of the PIVs as they are closely related to them. This study has shown that the majority of the specimens examined have IVVs (although not at all vertebral levels), which connect directly to the azygos vein rather than to the proximal part of the posterior intercostal veins.

De Brux et al (1995) showed that perfusion of the azygos vein in human cadavers leads to retrograde cerebral perfusion via the internal vertebral venous plexus. AV and PIV valves have been reported to be incompetent in previous studies (Herlihy, 1947; de Brux et al, 1995; Groen et al, 1997; Yeh et al, 2004; Ichikawa et al, 2008). Thus, it could be possible that IVVs that are connected exclusively to the AV could lead to retrograde drainage from the $A V$ into the vertebral venous system.

In the case reported by Gupta et al (2014), atypical drainage of PIVs into the azygos venous system was more common on the left side. They also showed that PIVs are variable in their course and termination, thus, intervertebral vein communications may also be variable. The present study revealed PIVs with adjacent IVVs directly draining into the azygos venous system instead of the proximal parts of the PIVs. These communications could play a role in regulating blood volume between the azygos and vertebral venous systems; they may also act as metastatic pathways between the abdominal and thoracic regions. As they mimic posterior intercostal vessels, it is important for surgeons to be aware of this variation to avoid injuries leading to postoperative hematomas.

It is acknowledged that this study had some limitations: the small IVVs could not be traced deeply as they were thin and susceptible to damage. In addition, it was not possible to measure the diameter of these small veins using digital calipers or to ascertain the direction of drainage. Dye injection into the azygos and vertebral venous systems may reveal the communications between them.

\section{Conflict of Interest}

The authors have no conflict of interest with the material or content of this manuscript. 


\section{Funding}

No funding or any financial support was received.

\section{Ethical Approval}

Not necessary.

\section{Informed Consent}

Not necessary.

\section{Contributionship}

Dissection, design, analysis and interpretation of data were undertaken by ND under the supervision of RS. The manuscript was written by ND and RS.

\section{REFERENCES}

de Brux JL, Subayi JB, Pegis JD. Pillet J. 1995. Retrograde cerebral perfusion: Anatomic study of the distribution of blood to the brain. Ann Thorac Surg 60: 1294-98.

Drake RL, Vogl W, Mitchell A, Gray H. 2005. Gray's Anatomy for Students, Philadelphia, Elsevier Churchill Livingstone, 197.

Groen RJM, Groenewegen HJ, van Alphen AM, Hoogland PVJM. 1997. Morphology of the human internal vertebral venous plexus: $A$ cadaver study after intravenous Araldite CY 221 injection. Anat Rec 249: 285-94.

Gupta RGD, Batra A, Swami S. 2014. Atypic drainage pattern of posterior intercostal veins into the azygos venous system. Int J Anat Res 2: 740-43.

Herlihy WF. 1947. Revision of the venous system: The role of the vertebral veins. Med J
Aus 1: 661-72.

Hoogland PV, Wessels Q, Vorster W, Groen RJM, Wettstein R, Greyling LM, Kotze SH. 2013. The posterior intercostal vein: a thermoregulatory gateway to the internal vertebral venous plexus. Clin Anat, 26: 735-40.

Ichikawa T, Endo J, Koizumi J, Ro A, Kobayashi M, Saito M, Kawada S, Hashimoto T, Imai Y. 2008. Visualization of the azygos arch valves on multidetector-row computed tomography. Heart Vessels 23: 118-23.

Maros T. 1981. Data regarding the typology and functional significance of the venous valves. Morphol Embryol 27: 195-214.

Snell R. 2004. Clinical Anatomy, Philadelphia, Lippincott, Williams and Wilkins, 132.

Standring S, Collins P, Crossman A, Gatzoulis M, Healy J, Johnson D, Mahadevan V, Newell R, Wigley C. 2008. Gray's Anatomy: The Anatomical Basis of Clinical Practice, Elsevier Churchill Livingstone, 205-10.

Yeh BM, Coakley FV, Sanchez HC, Wilson MW, Reddy GP, Gotway MB. 2004. Azygos arch valves: prevalence and appearance at contrast enhanced CT. Radiology 230: 111-15.

\section{ACKNOWLEDGEMENT}

The authors thank and respect all those who donated their bodies for scientific and medical education. ND also thanks the Centre for Anatomy and Human Identification (CAHID) for the opportunity to gain experience in dissecting Thiel-embalmed cadavers. 